Probleme der geschichtswissenschaftlichen Erkenntnis 



\section{Probleme der geschichtswissenschaftlichen Erkenntnis}

Herausgegeben von

Ernst Engelberg und Wolfgang Küttler

AKADEMIE-VERLAG · BERLIN

1977 
Akademie der Wissenschaften der DDR

Zentralinstitut für Geschichte

Redaktionelle Bearbeitung:

Hans-Peter Jaeck

Erschienen im Akademie-Verlag. 108 Berlin. Leipziger Str. 3-4 (c) Akademie-Verlag Berlin 1977

Lizenznummer: $202 \cdot 100 / 363 / 77$

Umschlaggestaltung: Rolf Kunze

Gesamtherstellung: VEB Druckerei .Thomas Müntzer”, 582 Bad Langensalza

Bestellnummer: $7530295(6340) \cdot$ LSV 0215

Printed in GDR

DDR 30,- M 